\title{
Cutaneous silent periods in multiple system atrophy
}

\author{
Ivana Stetkarovaa,b\#, Markus Koflerer ${ }^{\mathrm{t}}$, Veronika Majerova ${ }^{\mathrm{d}}$
}

\begin{abstract}
Aim. The cutaneous silent period (CSP) is a spinal inhibitory reflex primarily mediated by A-delta fibers. Prolonged CSPs have been reported in patients with restless legs syndrome (RLS) and idiopathic Parkinson's disease (IPD). Dopaminergic medication normalizes the CSP, concurring with the effect of levodopa on CSPs. To date, CSPs have not been extensively studied in patients with multiple system atrophy (MSA). The purpose of this study was to confirm abnormal CSP findings in a group of MSA patients and to affirm the lack of influence of levodopa on CSPs during long-term treatment. Methods. We investigated 15 patients (4 males, 11 females, age 58-71 years) who fulfilled the diagnostic criteria for possible MSA. Thirteen patients had predominant parkinsonian symptoms (MSA-P), 2 had predominant cerebellar signs (MSA-C). We recorded CSPs in thenar muscles following noxious digit II stimulation. Sixteen healthy volunteers (6 males, 10 females, range 24-56 years) served as control subjects for CSP recordings.

Results. Group average CSP onset was mildly delayed $(P<0.01)$, whereas CSP end latency $(P<0.001)$ were markedly delayed and CSP duration prolonged $(P<0.001)$ in MSA patients compared to healthy controls. MSA patients on levodopa treatment did not differ in their CSPs from those without levodopa. The dose of levodopa did not correlate to any CSP parameter.

Conclusion. The observed CSP prolongation corroborates previous findings in a limited number of MSA patients. The ineffectiveness of long-term levodopa on CSP abnormalities is consistent with its poor clinical effect in MSA.
\end{abstract}

Key words: multiple system atrophy, atypical parkinsonism, spinal reflex, cutaneous silent period, levodopa

Received: May 2, 2013; Accepted with revision: October 15, 2013, Available online: November 12, 2013 http://dx.doi.org/10.5507/bp.2013.081

${ }^{a}$ Department of Neurology, Third Faculty of Medicine, Charles University in Prague, Prague, Czech Republic ${ }^{b}$ Department of Neurology, Na Homolce Hospital, Prague

'Department of Neurology, Hochzirl Hospital, Zirl, Austria

${ }^{d}$ Department of Neurology and Center of Clinical Neuroscience, $1^{\text {st }}$ Faculty of Medicine, Charles University in Prague and General University Hospital in Prague, Prague

"The authors contributed equally to the work

Corresponding author: Ivana Stetkarova, e-mail: ivana.stetkarova@fnkv.cz

\section{INTRODUCTION}

Multiple system atrophy (MSA) is a sporadic and progressive neurodegenerative disorder characterized by autonomic failure in combination with parkinsonism or cerebellar ataxia. Apart from clinical diagnostic criteria ${ }^{1}$ neuroimaging studies may help in the differential diagnosis $^{2-5}$, as well as autonomic ${ }^{6}$ and neurophysiological testing $^{7-11}$ early on.

Cutaneous nerve electrical stimulation produces transient suppression of electromyographic (EMG) activity in a voluntarily contracted muscle in the same extremity, known as the cutaneous silent period (CSP) (ref. ${ }^{12,13}$ ). The afferent nerve fibers mediating the CSP are slowlyconducting A-delta fibers ${ }^{13,14}$. The exact neural mechanism of inhibition has yet to be elucidated; the CSP could be evoked either by postsynaptic inhibition of the motoneuron itself or through presynaptic inhibition of excitatory inputs to those motoneurons which sustain the voluntary contraction $^{12,15}$. Several characteristics of the CSP depend on physiological parameters, e.g. the combination of nerve stimulated and muscle recorded from ${ }^{13}$.

Altered CSPs have been demonstrated in movement disorders such as dystonia, idiopathic Parkinson's dis- ease (IPD), and restless legs syndrome (RLS) (ref. ${ }^{16-19}$ ). Dopaminergic medication can normalize the abnormalities in IPD (ref. ${ }^{18}$ ) and RLS (ref. ${ }^{19}$ ).

Four patients with MSA were reported with prolonged CSPs after a single levodopa challenge of $200-400 \mathrm{mg}$ $\left(\right.$ ref. $\left.{ }^{18}\right)$. These findings, however, have so far not been confirmed in a larger group of patients. We therefore investigated CSPs in a group of MSA patients who were on long-term levodopa treatment and compared findings with a group of MSA patients in whom levodopa was no longer to any avail and had therefore been terminated.

\section{MATERIALS AND METHODS}

We investigated 15 patients ( 4 males, 11 females, age 58-71 years) who fulfilled diagnostic criteria for possible MSA (ref. ${ }^{1}$ ) - a sporadic, progressive neurodegenerative disorder with onset after age 30 years, characterized by parkinsonism or a cerebellar syndrome, and at least one feature suggesting autonomic dysfunction (otherwise unexplained urinary urgency, frequency, or incomplete bladder emptying, erectile dysfunction in males, or significant orthostatic hypotension). Diagnosis was established in the 
Movement Disorders Center, Department of Neurology and Center of Clinical Neuroscience, Charles University in Prague, $1^{\text {st }}$ Faculty of Medicine and General University Hospital in Prague. No patient had a history or clinical evidence of a psychiatric disorder. Computed tomography or magnetic resonance imaging excluded tumors, lacunar infarcts, hydrocephalus, and subcortical ischemic encephalopathy. Sixteen healthy volunteers ( 6 males, 10 females, age 24 - 56 years) without evident history of neurological or psychiatric disorders and no recent intake of any medication served as control subjects. All participants granted informed consent. The study was approved by the local Ethics committee of $\mathrm{Na}$ Homolce Hospital, Prague, in compliance with the latest Declaration of Helsinki.

Neurophysiological investigation was performed with standard electrodiagnostic equipment (Dantec Keypoint, Dantec-Medtronic, Skovlunde, Denmark). Subjects lay supine with arms relaxed and hands held in a slightly pronated position with the fingers extended. CSPs were obtained bilaterally in all patients and in most control subjects, sequentially in right and left thenar muscles. Electrical square pulses $(0.5 \mathrm{~ms}$ duration, $0.5-0.7 \mathrm{~Hz}$ stimulation rate, 20 times the sensory threshold intensity) were delivered with ring electrodes located at the intermediate and distal phalanges of the index finger. Sensory thresholds were established in each subject as previously described $^{13}$. Stimuli were applied during isometric thumb abduction against a velcro strap on command for five seconds with self-estimated half-maximum strength. Visual and auditory feedback of the EMG signal was provided in order to facilitate control of muscle activity. Muscle force, however, has recently been shown to be less critical for CSP recordings than previously thought ${ }^{20,21}$. EMG activity was obtained with surface electrodes placed over abductor pollicis brevis muscle belly and tendon. Five single sweeps of $500 \mathrm{~ms}$ were recorded with filters set at 20 and $5000 \mathrm{~Hz}$. A CSP was defined as clear reduction or absence of voluntary EMG activity following the stimulus at appropriate latencies ${ }^{14,22}$. Mean values of five responses were calculated off-line for each patient. Unfortunately,

Table 1. Patient demographics.

\begin{tabular}{|c|c|c|c|c|c|c|c|c|}
\hline Number & $\begin{array}{c}\text { Age } \\
\text { [years] }\end{array}$ & Sex & Diagnosis & $\begin{array}{l}\text { Duration } \\
\text { of diseae } \\
\text { [months] }\end{array}$ & $\begin{array}{l}\text { L-dopa } \\
{[\mathrm{mg} / \mathrm{d}]}\end{array}$ & Reflexes & $\begin{array}{l}\text { Pyramidal } \\
\text { signs }\end{array}$ & Co-morbidities \\
\hline 1 & 66 & $\mathrm{~F}$ & MSA-P & 21 & 0 & $\begin{array}{l}\text { Hyporeflexia } \\
\text { L2-S2 }\end{array}$ & None & \\
\hline 2 & 71 & M & MSA-P & 66 & 0 & Normal & None & Diabetes mellitus type II, on diet \\
\hline 3 & 58 & M & MSA-P & 34 & 600 & $\begin{array}{l}\text { Hyporeflexia } \\
\text { L5-S2 }\end{array}$ & None & \\
\hline 4 & 57 & $\mathrm{~F}$ & MSA-P & 16 & 1000 & Normal & None & \\
\hline 5 & 70 & $\mathrm{~F}$ & MSA-P & 51 & 350 & $\begin{array}{l}\text { Areflexia } \\
\text { L5-S2 }\end{array}$ & $\begin{array}{l}\text { Babinski } \\
\text { bilateral }\end{array}$ & $\begin{array}{l}\text { Cervical spondylotic stenosis at C5-C7 } \\
\text { level }\end{array}$ \\
\hline 6 & 66 & $\mathrm{~F}$ & MSA-P & 49 & 1500 & $\begin{array}{l}\text { Normal } \\
\text { L2-S2 }\end{array}$ & $\begin{array}{l}\text { Hyperreflexia } \\
\text { C5-C8 }\end{array}$ & Thyreopathy \\
\hline 7 & 65 & M & MSA-P & 80 & 825 & Normal & None & \\
\hline 8 & 65 & $\mathrm{~F}$ & MSA-P & 85 & 0 & $\begin{array}{l}\text { Hyporeflexia } \\
\text { L2-S2 }\end{array}$ & $\begin{array}{l}\text { Babinski } \\
\text { right }\end{array}$ & \\
\hline 9 & 63 & $\mathrm{~F}$ & MSA-P & 47 & 750 & Normal & None & Thyreopathy \\
\hline 10 & 55 & $\mathrm{~F}$ & MSA-P & 32 & 1475 & $\begin{array}{l}\text { Hyporeflexia } \\
\text { L5-S2 }\end{array}$ & None & \\
\hline 11 & 61 & $\mathrm{~F}$ & MSA-P & 46 & 1450 & $\begin{array}{l}\text { Hyporeflexia } \\
\text { L5-S2 }\end{array}$ & None & \\
\hline 12 & 59 & $\mathrm{~F}$ & MSA-P & 57 & 0 & $\begin{array}{l}\text { Normal } \\
\text { C5-8 }\end{array}$ & $\begin{array}{l}\text { Hyperreflexia } \\
\text { L2-L4 }\end{array}$ & \\
\hline 13 & 62 & M & MSA-C & 30 & 0 & $\begin{array}{l}\text { Areflexia } \\
\text { L5-S2 }\end{array}$ & None & $\begin{array}{l}\text { Diabetes mellitus type II, on insuline, } \\
\text { lumbar spondylotic stenosis at L3-L5 } \\
\text { level }\end{array}$ \\
\hline 14 & 69 & $\mathrm{~F}$ & MSA-P & 49 & 0 & Normal & None & \\
\hline 15 & 64 & $\mathrm{~F}$ & MSA-C & 76 & 125 & Normal & $\begin{array}{l}\text { Babinski } \\
\text { bilateral }\end{array}$ & \\
\hline
\end{tabular}


Table 2. Autonomic dysfunction and magnetic resonance imaging findings.

\begin{tabular}{|c|c|c|c|c|}
\hline Number & $\begin{array}{l}\text { Sphincter } \\
\text { dysfunction }\end{array}$ & $\begin{array}{c}\text { Orthostatic } \\
\text { hypothension }\end{array}$ & $\begin{array}{l}\text { Tilt table } \\
\text { test }\end{array}$ & $\begin{array}{l}\text { Brain } \\
\text { MRI }\end{array}$ \\
\hline 1 & - & + & n.r. & Discrete putaminal atrophy \\
\hline 2 & + & - & - & - \\
\hline 3 & + & + & - & - \\
\hline 4 & + & + & + & - \\
\hline 5 & + & + & + & Discrete putaminal atrophy \\
\hline 6 & + & - & - & Putaminal changes \\
\hline 7 & + & + & + & Pontine and putaminal atrophy \\
\hline 8 & + & + & + & - \\
\hline 9 & + & + & + & n.r. \\
\hline 10 & - & + & - & Lamellar atrophy of cerebellum \\
\hline 11 & + & - & n.r. & - \\
\hline 12 & - & - & - & Putaminal changes, middle cerebellar peduncle atrophy \\
\hline 13 & + & - & - & Putaminal changes, middle cerebellar peduncle atrophy \\
\hline 14 & + & - & - & Pontine atrophy \\
\hline 15 & + & $\mathrm{n}$ & n.r. & $\begin{array}{l}\text { Putaminal changes, } \\
\text { pontine atrophy, } \\
\text { middle cerebellar peduncle atrophy, } \\
\text { cerebellar atrophy }\end{array}$ \\
\hline
\end{tabular}

n.r. $=$ not recorded

Table 3. Cutaneous silent period (CSP) parameters in patients with multiple system atrophy ( $\mathrm{n}=15)$ and healthy control subjects $(n=16)$; mean \pm standard error; Mann-Whitney-U test.

\begin{tabular}{lcccc}
\hline & & Patients & Controls & $P$ value \\
\hline Number of limbs studied & & 29 & 23 & 0.016 \\
CSP onset & {$[\mathrm{ms}]$} & $82.7 \pm 2.4$ & $74.5 \pm 1.5$ & $<0.001$ \\
CSP duration & {$[\mathrm{ms}]$} & $77.2 \pm 4.7$ & $50.5 \pm 2.2$ & $<0.001$ \\
CSP end & {$[\mathrm{ms}]$} & $159.8 \pm 4.2$ & $125.0 \pm 2.2$ & \\
\hline
\end{tabular}

the equipment did not allow for rectification of the raw EMG signal, so that appropriate "on-line" averaging of the EMG traces without phase cancellation was not possible.

Statistical analysis was performed with SPSS 20.0 (IBM SPSS Inc., Chicago, IL, USA). Mean \pm standard error was calculated from all mean values obtained in each subject and compared with Mann-Whitney-U test between groups. Spearman correlation was calculated for each parameter (onset and end latency, as well as duration of CSPs) in order to identify any significant changes relative to levodopa dose. A $P$-value of $<0.025$ was considered significant.

\section{RESULTS}

All patients and healthy controls were able to complete the study. Patient demographics are shown in Table 1. Most patients presented with sphincter dysfunction and orthostatic problems. Cerebral MRI findings included middle cerebellar peduncle atrophy and/or lamellar atrophy of the cerebellum, as well as pontine and putaminal atrophy (Table 2). Thirteen patients had predominant parkinso- nian symptoms (MSA-P), two had predominant cerebellar signs (MSA-C), consistent with a known preponderance for MSA-P in Europe ${ }^{23}$. One patient with cervical myelopathy had an absent CSP on the right side, which is not unusual even in mild cervical spondylotic myelopathy ${ }^{24}$. Nine patients were on levodopa treatment with an average of $897 \mathrm{mg} / \mathrm{d}$. No patient received dopamine agonists. Signs of upper motoneurone lesion (Babinski sign, hyperreflexia) were noted in five patients (9 limbs); signs of lower motoneurone lesion (hyporeflexia, areflexia) were noted in seven patients ( 14 limbs) (ref. ${ }^{11}$ ). No patient had a history or clinical evidence of radiculopathy. One patient also had insulin-dependent diabetes mellitus.

CSP onset and end latencies were significantly delayed and CSP duration was significantly prolonged in patients as compared to healthy control subjects (Table 3 ). There was no difference in CSP parameters between patients taking levodopa $(n=9)$ and those who were not $(n=6)$ : CSP onset latency: $83.5 \pm 2.7 \mathrm{~ms}$ versus $86.4 \pm 4.0 \mathrm{~ms}$; CSP duration: $69.9 \pm 6.3 \mathrm{~ms}$ versus $68.9 \pm 4.3 \mathrm{~ms}$; CSP end latency: $157.4 \pm 5.1 \mathrm{~ms}$ versus $155.3 \pm 4.4 \mathrm{~ms}(P>0.5 \mathrm{each})$. Furthermore, there was no correlation of levodopa medication to any of the CSP parameters (onset: $\rho=-0.348$; 
duration: $\rho=0.121$; end: $\rho=-0.70 ; P>0.06$ each), despite similar disease duration (mean \pm standard deviation) in patients with and without levodopa $(47.9 \pm 19.7$ versus $51.3 \pm 22.4$ months, $P>0.5)$. Findings in the two patients with MSA-C were not consistently different from those in patients with MSA-P. No formal statistical comparison, however, was performed between MSA-C and MSA-P due to the inhomogeneous distribution. Representative examples are shown in Fig. 1.

\section{DISCUSSION}

MSA is a rare progressive neurodegenerative disorder presenting with extrapyramidal, cerebellar, pyramidal and autonomic signs. Early recognition of this disease has important implications for a patient's medical treatment and clinical management. Magnetic resonance imaging and diffusion tensor imaging are the key diagnostic methods to differentiate MSA from IPD (ref. ${ }^{2-4}$ ), however, simple neurophysiological testing could aid in the early differential diagnostic process $^{7-11}$.

This study describes delayed CSP onset and prolonged CSP duration in 15 patients with MSA, thus confirming previously reported findings in a smaller sample of four MSA patients. Furthermore, long-term levodopa exerted no significant influence on any CSP parameter, concurring with its poor clinical efficacy in this disorder. We

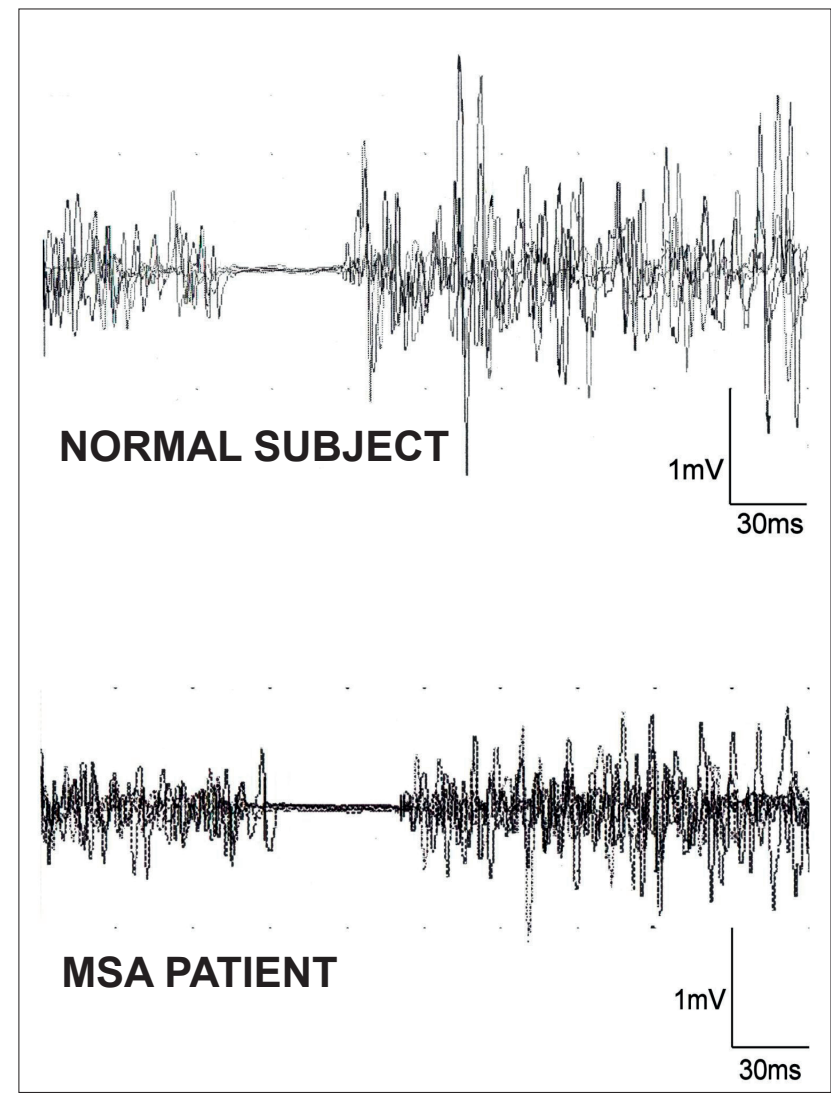

Fig. 1. Representative examples of cutaneous silent periods in a normal subject (upper panel) and a patient with multiple system atrophy (lower panel). refrained from performing an additional levodopa challenge, as this had already been done in those patients without levodopa treatment without clinical effect, and it has been described in the literature: Serrao et al. ${ }^{18}$ reported an acute levodopa challenge of 200 to $400 \mathrm{mg}$ without effects on UPDRS scores or on CSP duration in their four patients with MSA. In the present study, patients receiving long-term levodopa up to $1500 \mathrm{mg}$ daily did not differ significantly in any CSP parameter from patients without levodopa.

To date, reports on dopaminergic influence on cutaneomuscular reflexes have been controversial: opposite effects were reported in RLS (ref. ${ }^{19,25}$ ), as well as in IPD (ref. ${ }^{18,26,27}$ ). Part of this discrepancy favors distinct spinal inhibitory circuitry mediated by low- and high-threshold afferents ${ }^{13,18,28-30}$, with the possibility that dopaminergic influence is exerted only on low-threshold afferent circuitry. The latter may contribute to the electrically evoked CSP (ref. ${ }^{28}$ ) due to concomitant activation of low-threshold afferents which inevitably occurs when applying electrical stimuli to peripheral nerves.

On the other hand, CSPs evoked by the same type of electrical stimulation to the index finger were similarly prolonged in IPD and MSA, while only in IPD patients levodopa shortened the CSPs to normal durations. This strongly implies an effect of basal ganglia on spinal excitability which is deficient in MSA, a disorder characterized by poor or entirely absent effect of dopaminergic medication $^{31}$. Basal ganglia exert well-known modulatory influences on brainstem circuitry such as the blink reflex ${ }^{23,32}$ and the auditory startle reaction. MSA patients in particular are characterized by exaggerated auditory startle reactions ${ }^{9}$, a finding also seen to a lesser extent in patients with RLS (ref. ${ }^{33}$ ). Thus, the basal ganglia likely influence spinal excitability at least in part via reticulospinal pathways. Reticulospinal neurons are also known to be involved in flexor withdrawal reflexes, which are also disinhibited in RLS (ref. ${ }^{34}$ ). Flexor withdrawal reflexes likely share common spinal circuitry with CSPs. In fact, both are evoked by A-delta fibers, they have a similar distribution among various limb muscles in upper and lower extremities, and both are involved in protective movement behavior $^{22,35}$. Thus the reticulospinal system may in fact be a common link interposed between basal ganglia and spinal cord with respect to dopaminergic influence on spinal inhibitory circuitry which causes increased excitability or reduced inhibition, thus leading to shortened CSP duration.

Delayed onset of the CSP has previously been attributed to dysfunction of corticospinal neurons based on findings in stroke, amyotrophic lateral sclerosis and cervical compressive myelopathy ${ }^{24,36}$. Arguably it seems difficult to envision how a motor pathway that is inhibited by A-delta afferent input can facilitate the same circuitry in a way that the onset of its own inhibition is preponed. But up to this point no better explanation has been offered. An alternative contribution to a delay in CSP onset could derive from large-diameter efferent fiber polyneuropathy, an often underrecognized feature of MSA (ref. ${ }^{13}$ ). Alpha- 
motoneurones convey input from the spinal cord to the muscles; thus when they conduct more slowly, their inhibition would also become apparent later. Finally, our normal subjects were younger, which may also explain some minor effect on the results, as a mild effect of age on CSP duration has been reported ${ }^{37}$. The findings reported here, however, clearly exceed possible age-associated effects. To date, little is known about neurotransmitters involved in CSP generation. Previous studies indicated no influence of benzodiazepines (diazepam) (ref. $\left.{ }^{38}\right)$, opiates (fentanyl) (ref. ${ }^{39}$ ), antihistaminics (cetirizine) $\left(\right.$ ref. $\left.{ }^{40}\right)$, or $\mathrm{GABA}_{\mathrm{B}}$ agonists (baclofen) (ref. $\left.{ }^{38,41,42}\right)$. Recently, increased CSP duration following tramadol application has been attributed to its monoaminergic action leading to inhibition of serotonin and noradrenaline reuptake ${ }^{43}$.

In summary, patients with MSA present with delayed and prolonged CSPs in comparison to healthy control subjects. These CSP abnormalities are not normalized, unlike in patients with IPD, by acute or chronic levodopa administration, and this concurs with the poor clinical response to levodopa in MSA. It remains to be tested whether the ineffectiveness of levodopa on CSP alteration can have clinical value in the differential diagnosis of MSA.

\section{ACKNOWLEDGMENTS}

Supported by Grant of Czech Ministry of Health IGANT 12282 and Research Project of Charles University of Prague PRVOUK P 34.

The authors express their gratitude to Ellen Quirbach, Hochzirl, for providing editorial help with the manuscript.

Author contributions: IS, MK: literature search and manuscript writing; IS: study design; IS, VM: data collection and analysis; IS, VM, MK: data interpretation; IS, MK: statistical analysis, figures; IS: final approval.

Conflict of interest statement: None declared.

\section{REFERENCES}

1. Gilman S, Wenning GK, Low PA, Brooks DJ, Mathias CJ, Trojanowsk JQ, Wood NW, Colosimo C, Dürr A, Fowler CJ, Kaufmann H, Klockgether T, Lees A, Poewe W, Quinn N, Revesz T, Robertson D, Sandroni P, Seppi K, Vidailhet M. Second consensus statement on the diagnosis of multiple system atrophy. Neurology 2008;71:670-6.

2. Grambalova P, Hlustik P, Herman M, Kanovsky P. The occurrence of "typical" MRI findings in progressive supranuclear palsy and multiple system atrophy - a retrospective pilot study. Cesk Slov Neurol N 2010;73/106:538-41.

3. Nair SR, Tan LK, Mohd Ramli N, Lim SY, Rahmat K, Mohd Nor H. A decision tree for differentiating multiple system atrophy from Parkinson's disease using 3-T MR imaging. Eur Radiol 2013;23(6):1459-66.

4. Wadia PM, Howard P, Ribeirro MQ, Robblee J, Asante A, Mikulis DJ, Lang AE. The Value of GRE, ADC and Routine MRI in Distinguishing Parkinsonian Disorders. Can J Neurol Sci 2013; 40(3):389-402.

5. Umemura A, Oeda T, Hayashi R, Tomita S, Kohsaka M, Yamamoto K, Sawada H. Diagnostic accuracy of apparent diffusion coefficient and 123I-metaiodobenzylguanidine for differentiation of multiple system atrophy and Parkinson's disease. PLoS One 2013;8 (4):e61066.

6. Kimpinski K, lodice V, Burton DD, Camilleri M, Mullan BP, Lipp A, Sandroni P, Gehrking TL, Sletten DM, Ahlskog JE, Fealey RD, Singer $\mathrm{W}$, Low PA. The role of autonomic testing in the differentiation of
Parkinson's disease from multiple system atrophy. J Neurol Sci 2012; 317:92-6.

7. Valls-Solé J. Neurophysiological characterization of parkinsonian syndromes. Neurophysiol Clin 2000;30:352-67.

8. Valls-Solé J, Veciana M, Leon L, Valldeoriola F. Effects of a startle on heart rate in patients with multiple system atrophy. Mov Disord 2002;17(3):546-9.

9. Kofler M, Müller J, Seppi K, Wenning GK. Exaggerated auditory startle responses in multiple system atrophy: a comparative study of parkinson and cerebellar subtypes. Clin Neurophysiol 2003;114(3):5417

10. Podnar S, Fowler CJ. Sphincter electromyography in diagnosis of multiple system atrophy: Technical issues. Muscle Nerve 2004;29(1):151-6.

11. Gawel M, Jamrozik Z, Szmidt-Salkowska E, Slawek J, RowinskaMarcinska K. Is peripheral neuron degeneration involved in multiple system atrophy? A clinical and electrophysiological study. J Neurol Sci 2012;319:81-5.

12. Inghilleri M, Cruccu G, Argenta M, Polidori L, Manfredi M. Silent period in upper limb muscles after noxious cutaneous stimulation in man. Electroencephalogr Clin Neurophysiol 1997;105:109-15.

13. Kofler M. Functional organization of exteroceptive inhibition following nociceptive electrical fingertip stimulation in humans. Clin Neurophysiol 2003;114:973-80.

14. Leis $A A$, Kofler M, Ross MA. The silent period in pure sensory neuronopathy. Muscle Nerve 1992;15:1345-8.

15. Leis AA, Štetkárová I, Beric A, Stokic DS. Spinal motor neuron excitability during the cutaneous silent period. Muscle Nerve 1995;18:1464-70.

16. Pullman SL, Ford B, Elibol B, Uncini A, Su PC, Fahn S. Cutaneous electromyographic silent period findings in brachial dystonia. Neurology 1996;46:503-8

17. Nakashima K, Takahashi K. Silent periods in the abductor pollicis brevis muscle in patients with Parkinson's disease. Electromyogr Clin Neurophysiol 1992;32:215-9.

18. Serrao M, Parisi L, Valente G, Martini A, Fattapposta F, Pierelli F, Rossi F. L-Dopa decreases cutaneous nociceptive inhibition of motor activity in Parkinson's disease. Acta Neurol Scand 2002;105:196-201.

19. Han JK, Oh K, Kim BJ, Koh SB, Kim JY, Park KW, Lee DH. Cutaneous silent period in patients with restless leg syndrome. Clin Neurophysiol 2007;118:1705-10.

20. Kofler M, Kumru H, Štetkárová I, Schindler C, Fuhr P. Muscle force up to $50 \%$ of maximum does not affect cutaneous silent periods in thenar muscles. Clin Neurophysiol 2007;118:2025-30.

21. Rodi Z, Springer C. Influence of muscle contraction and intensity of stimulation on the cutaneous silent period. Muscle Nerve 2011;43:324-8

22. Svilpauskaite J, Truffert A, Vaiciene N, Magistris MR. Electrophysiology of small peripheral nerve fibers in man. A study using the cutaneous silent period. Medicina (Kaunas) 2006;42:300-13.

23. Köllensperger M, Geser F, Ndayisaba JP, Boesch S, Seppi K, Ostergaard K, Dupont E, Cardozo A, Tolosa E, Abele M, Klockgether T, Yekhlef F, Tison F, Daniels C, Deuschl G, Coelho M, Sampaio C, Bozi M, Quinn N, Schrag A, Mathias CJ, Fowler C, Nilsson CF, Widner H, Schimke N, Oertel W, del Sorbo F, Albanese A, Pellecchia AM, Barone P, Djaldetti R, Colosimo C, Meco G, Gonzalez-Mandly A, Berciano J, Gurevich T, Giladi N, Galitzky M, Rascol O, Kamm C, Gasser T, Siebert U, Poewe W, Wenning GK, on behalf of the EMSA-SG. Presentation, diagnosis, and management of multiple system atrophy in Europe: Final analysis of the European multiple system atrophy registry. Mov Disord 2010;25(15):2604-12.

24. Štetkárová I, Kofler M. Cutaneous silent periods in the assessment of mild cervical spondylotic myelopathy. Spine 2009;34:34-42.

25. Öz O, Erdogan C, Yücel M, Akgün H, Kütükcü Y, Gökcil Z, Odabaşi Z. Effect of pramipexole on cutaneous-silent-period parameters in patients with restless legs syndrome. Clin Neurophysiol 2012;123:1549.

26. Fuhr P, Zeffiro T, Hallett M. Cutaneous reflexes in Parkinson's disease. Muscle Nerve 1992;15:733-9.

27. Clouston PD, Lim CL, Sue C, Morris JGL, Yiannikas C. Apomorphine can increase cutaneous inhibition of motor activity in Parkinson's disease. Electroencephalogr Clin Neurophysiol 1996;101:8-15.

28. Kofler M, Fuhr P, Leis AA, Glocker FX, Kronenberg MF, Wissel J, Stetkarova I. Modulation of upper extremity motor evoked po- 
tentials by cutaneous afferents in humans. Clin Neurophysiol 2001;112:1053-63.

29. Serrao M, Parisi L, Pierelli F, Rossi P. Cutaneous afferents mediating the cutaneous silent period in the upper limbs: evidences for a role of low-threshold sensory fibres. Clin Neurophysiol 2001;112:2007-14.

30. Floeter MK. Cutaneous silent periods. Muscle Nerve 2003;28:391401.

31. Colosimo C, Tiple D, Wenning GK. Management of multiple system atrophy: state of the art. J Neural Transm 2005;112:1695-1704.

32. Kimura J. Disorder of interneurons in Parkinsonism. The orbicularis oculi reflex to paired stimuli. Brain 1973;96:87-96.

33. Frauscher B, Löscher W, Högl B, Poewe W, Kofler M. Auditory startle reaction is disinhibited in idiopathic restless legs syndrome. Sleep 2007;30:489-93.

34. Bara-Jimenez W, Aksu M, Graham B, Sato S, Hallett M. Periodic limb movements in sleep: state-dependent excitability of the spinal flexor reflex. Neurology 2000;54:1609-15.

35. Floeter MK, Gerloff C, Kouri J, Hallett M. Cutaneous withdrawal reflexes of the upper extremity. Muscle Nerve 1998;21:591-8.

36. Gilio F, Bettolo CM, Conte A, lacovelli E, Frasca V, Serrao M, Giacomell E, Gabriele M, Prencipe M, Inghilleri M. Influence of the corticospinal tract on the cutaneous silent period: A study in patients with pyramidal syndrome. Neurosci Lett 2008;433:109-13.
37. Koo JS, Park HR, Joo BE, Choi JY, Jung KY, Park KW, Cho SC, Kim BJ. Utility of the cutaneous silent period in the evaluation of carpal tunnel syndrome. Clin Neurophysiol 2010;121 (9):1584-8.

38. Inghilleri M, Berardelli A, Marchetti P, Manfredi M. Effects of diazepam, baclofen and thiopental on the silent period evoked by transcranial magnetic stimulation in humans. Exp Brain Res 1996;109:467-72.

39. Inghilleri M, Conte A, Frasca V, Berardelli A, Manfredi M, Cruccu G. Is the cutaneous silent period an opiate-sensitive nociceptive reflex? Muscle Nerve 2002;25:695-9.

40. Kofler M, Kumru H, Stetkarova I, Ruegg S, Fuhr P, Leis AA. Cutaneous silent periods are not affected by the antihistaminic drug cetirizine. Clin Neurophysiol 2009;120:1013-6.

41. Kofler M, Wissel J, Müller J, Brenneis C. Influence of intrathecal baclofen on silent periods in dystonia. Muscle Nerve 2000;23:1145-6.

42. Stetkarova I, Kofler M. Differential effect of baclofen on cortical and spinal inhibitory circuits. Clin Neurophysiol 2013;124:339-45.

43. Pujia F, Coppola G, Anastasio MG, Brienza M, Vestrini E, Valente GO, Parisi L, Serrao M, Pierelli F. Cutaneous silent period in hand muscles is lengthened by tramadol: Evidence for monoaminergic modulation? Neurosci Lett 2012;528:78-82. 